\title{
The Effect of Using Detailed Electronic Feedback on some Biomechanical Indicators and the Skill Level of High Jump Players
}

\section{Mohamed Mustafa Al-Saeed Al-Jundi}

Lecturer in Teaching Methodologies and Curricula Department at the Faculty of Physical Education - Fayoum University.

\section{Abstract}

This research conspicuously aims to try to identify the effect of using detailed electronic feedback on some biomechanical indicators and the level of skill performance of high jump players. Besides, the research sample was in the field of athletic sports in the Faculty of Physical Education, Fayoum University. Moreover, the researcher used the experimental approach through using the experimental design of one experimental group through pre and post measurement on the research sample of (6) players from the specialization of athletic sports and registered in the Egyptian Federation of Athletic Sports. The researcher also used (3) players from the Fayoum Governorate club and registered in the Egyptian Athletics Federation and from the same age as an exploratory study. The researcher conducted homogeneity for each of the experimental and exploratory groups through conducting scientific transactions for the tests under study. The results indicated that the use of detailed electronic feedback had an efficacy and a positive role in improving some biomechanical indicators of the two stages of upgrading and flying in the high jump, which led to an improvement in the level of skill performance of high jump players as well as for feedback. The detailed effect size ranged from medium to large for some biomechanical indicators of the upgrading and flight stages of the high jump, as well as the size of a large impact on the level of skill performance of the high jump.

Key words: Electronic Detailed Feedback, Biomechanical Indicators, High Jump.

\section{Introduction and Research Problem}

The scientific progress in the information technology revolution has conspicuously become one of the most important features of the era in which we live and which extended to all branches and fields of different sciences. Consequently, it makes us keep pace with this development, guide it, live with it and simulate it until we become an integral part of the life of modern societies and the educational process in light of the modern technological age. Besides, it relies strongly on modern educational techniques. Feedback is one of the scientific items that occupy great importance in the field of teaching as it is one of the most important scientific and practical foundations. Moreover, it provides the student with positive and negative information about kinetic performance contributes to reaching the mastery of the skill, as this information is represented by feedback which takes multiple forms, including verbal and visual, which give the learner a clear image of what he does while applying the skill with the eye. Therefore, he can correct his mistakes according to the information he receives from the teacher pre and during the application.

Additionally, feedback is the most important fruit of the evaluation process, whereby the learner is provided with detailed information about the nature of his learning. Thus, the role that feedback plays in education stems from the principles of relational and behavioral theories that confirm the fact that the individual changes his behavior when he knows the results of those previous behaviors. Those theories assert on the promoting role of feedback. It works to stimulate the motivation of the learner, directing his energies towards learning, as they contribute to the confirmation and consolidation of information and thus help to raise the level of performance in the subsequent educational tasks. On this basis, the immediate feedback 
constitutes an important and effective role in learning these missions as it is one of the most important sources that provide the learner with information that works to correct mistakes. (Wahab, 2009, p. 569)

In the learning environment of electronic projects, the learner needs guidance, direction and feedback during and after his studies. Among the elements of building the learning environment in electronic projects is the electronic feedback provided to him in its various forms, and because the feedback has become an essential element in all learning contexts, many studies have dealt with different types of feedback. For example: the study of (Lemley, D., Sudweeks, R., Howell, S.R., \& Laws, D.O., 2007), (Brookhart, S.M., 2008), (Nussabaumer, A. \& Kravcik and Albert, D., 2012), (Ramoud, 2013) Some of it is based on the source of the feedback (internal or sensory subjective, and external). The internal or intrinsic feedback is sensory: it is the information that comes from internal sensory sources, such as the sense of balance in gymnasts, or when muscle cramping occurs for soccer players. The player feels internal pain in the muscle. The second type is external feedback: it is. According to its name, it is external to the body, and comes from external sources such as the processes directed by the coach or teacher, including what is based on the time period between response and providing feedback (immediate and deferred). It is also includes what is based on the form of information (verbal and non-verbal). Besides, it is classified according to the level of presentation (brief, detailed). The current research will be limited to detailed feedback. Detailed feedback is a process that clarifies and explains the learner's response, whether it is correct or wrong. It also explains and clarifies the causes of the error, and provides the learner with directions and instructions necessary to reinforce, develop, or correct the behavior. (Lemley, D., Sudweeks, R., Howell, S.R., \& Laws, D.O., 2007), (Brookhart, S.M., 2008), (Nussabaumer, A. \& Kravcik and Albert, D., 2012),

\section{- Detailed Feedback}

Detailed feedback is the information provided to the learner as a result of his making a mistake with the intention of helping him to correct his performance and his response, by informing the learner about the entire alternative behavior model and in all its details, especially providing explanations, interpretations and evidence about the procedure, process, or step. (Smits, M.H., Boon, J.O., \& Sluijsmans, D.M. , 2008, p. 189), (Hendry, G.D., Bromberger, N., \& Armstrong, S., 2011).

Moreover, detailed feedback can be provided in a number of ways. It can provide learners with the knowledge of a correct response and is actually used to provide information about correct or incorrect responses. (Mason, J.B. \& Bruning, R., 2011).

The word "detailed" also refers to any additional information that goes beyond the verification process. It may also be called explained or extended feedback. (Valdez, A., 2012).

There are those who describe the detailed feedback as: "Comprehensive information about the learner's performance in solving the problem with providing details of each step that is taken in order to obtain the correct answer for future tasks. This information is given to the learner after his response so that he can know the correctness of his response to the educational task". (Al-Jazzar, 2014, p. 59)

It can also be said that it is: "A general plan consisting of a set of educational activities and procedures that focus mainly on feedback of a detailed type that depends on additional and confirming information for the learner about his performance, followed by the learner in order to achieve his predetermined goals". (Fakhry, 2017, p. 75)

The detailed electronic feedback has a distinct position among the research related to 
educational technology, because it is considered one of the most practices that teachers use when designing electronic learning environments, because it is based on achieving the outputs of the educational process. It represents one of the pillars on which the learner evaluation processes depend. Because it informs him of his progress in the learning process, and gives him an image of his performance in different educational situations. The detailed electronic feedback is also one of the important elements of effective education, which in turn affects the motivation of the learner. Besides, it is an important means of social interaction that stems from the principles of relational and behavioral theories which emphasize the fact that the individual changes his behavior when he knows the results of his previous behavior. Thus, the theories confirm the reinforcing role of the electronic detailed feedback, and that it works to stimulate the motivation of the learner and direct his energies towards learning, as it contributes to the stabilization of information, and thus helps to raise the level of performance on educational tasks. (Mohammed, 2017, p. 4)

The importance of detailed feedback is as follows:

1. The development of practical skills: as it supports the learner's skills in various practical activities. The study of both of (Kafafi, 2009), (Walsh, D., 2010) asserts that electronic feedback was better in improving learners' errors and developing their different skills concerning traditional feedback.

2. Evaluating Learners: to help, improve, develop and progress their abilities in order to increase their self-confidence, strive to develop teamwork, and develop communication skills with learners and with the teacher, as well as a sense of personal satisfaction (Duffy, K., 2013, p. 32)

3. Activating Learning Process: Feedback is important as it increases the level of motivation to learn, and makes both teachers and learners in constant movement to achieve the desired goals. ( Jamal al-Din, 2017, p. 38)

are:

The detailed feedback has many characteristics that define and shape its entity, which

1. Reinforcement: It is considered a major pillar in the functional performance of the feedback. It leads to informing the learner of the correctness of his response, and increases the likelihood of repeating the correct response later.

2. Motivation: it is considered an important axis because it contributes to stimulating the learner's motivation for achievement, learning and performance involved.

3. Directed: it works to direct the learner towards his performance, showing him the perfect performance in order to assert it, and the incomplete performance in order to avoid it. Thus, it raises the level of the learner's attention in order to avoid his weaknesses and shortcomings. (Abdul Karim, 2006, p. 369), (Al-Halafawi, 2008, p. 133), (Muhammad, 2008)

Most of the sources and studies have agreed to divide the technical performance of the high jump into four main stages:

- Approach Stage

- Take-off stage

- flight and bar clearance stage Stage

- Landing stage

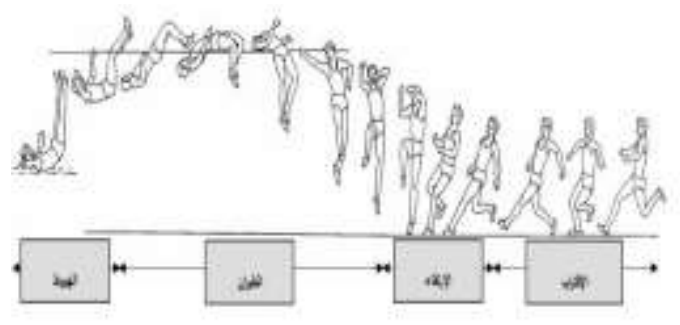


Moreover, previous references and studies indicate that the two stages of upgrading and flying are among the most important stages that affect the level of skill performance of the high jump. Thus, this study will focus on giving detailed electronic feedback in these two stages and knowing its effect on some biomechanical variables and the level of skill performance of the stages of upgrading and flying in high jump.

\section{- Take-off stage}

The Take-off stage starts from the moment when the player's foot touches the ground at the end of the approach to the moment when the player leaves the ground. The Take-off stage is of great importance in the success of the jump, as the upgrade is the stage of linking the horizontal and vertical movement and its success reflects the success of the jump as a whole. Besides, the stage of upgrading is divided into three moments, which are the moment of touch damping moment- the moment when contact with earth is broken.

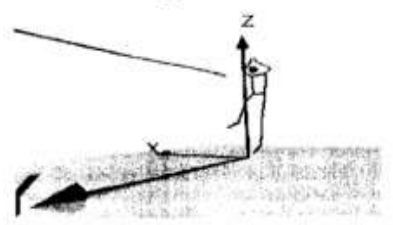

No ground contact moment

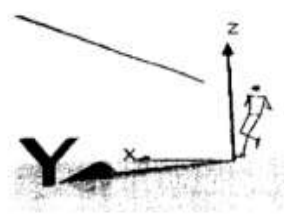

Damping Moment

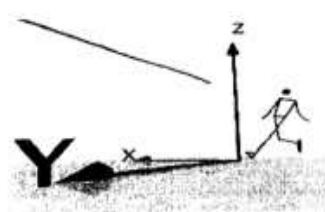

Ground contact moment (Al-Badri, 2015, p. 66), (Badran, 2015, p. 153), (Hassan \& Al-Badri, 2015, p. 74)

\section{- flight and bar clearance stage Stage}

After completing the upgrading process, the player rotates his body after moving in the direction of the upper front so that the axis of the shoulders and the pelvis rotates on the crossbar. Besides, the rotation process takes place on the three axis of the body (the longitudinal axis, the lateral axis and the transverse axis). The player, at this stage, pulls the free foot to the side of the upgrading feet. The hands are pulled next to the body in order to help the body rotate along the longitudinal axis. Then, the player moves up and back facing the crossbar. Moreover, the player must rotate his head towards the crossbar in order to direct the movement and after crossing the crossbar's shoulders, the thighs start to be pulled over the bar with a quick movement, and the player's body becomes in the form of an arc over the crossbar. The crossbar is crossed by bending the knees at a right angle after crossing the thighs and as soon as the legs approach the crossbar at the knees quickly with a wave movement in the thighs and knees to reach the end of the body of the L-shaped jumper in preparation for falling-down. The process of crossbar is done from the head till the two legs through the arms drop down from the side of the torso. (Al-Daly, 2017, p. 45)

The high jump competition is considered one of the competitions that require a great deal of high jumping compound skills, which depends mainly on the level of balance and stability of the high jump competitor during the Take-off stage and flying. The result is achieving high levels of ability to perform well. Additionally, the kinetic imbalance of the competitor during the upgrade phase does not enable him to take out all of his ability during the flight phase.. (AlDaly, 2017, p. 47)

Through the researcher's experience, his follow-up of the various high jump competitions, and his theoretical reading of references and scientific research, whether Arab or foreign, the researcher intended to conduct an applied scientific study to identify the effect of using electronic detailed feedback on some biomechanical indicators and the level of skill performance of high jump players.

Whereas, the detailed electronic feedback provides information that explains the learner's 
response, whether correct or wrong, and it treats the wrong responses, and the effectiveness of the electronic detailed feedback increases whenever the learner has an appropriate cognitive structure that enables him to judge the correctness or error of the information provided to him. It can be said that the detailed electronic feedback is informing the student of the result of his learning by providing him with information on the progress of his performance on an ongoing basis, to help him to establish that performance, if he is moving in the right direction, or to amend it if it needs to be modified. This indicates the connection of the concept of detailed electronic feedback with the comprehensive concept of the evaluation process as one of the means used in order to ensure the achievement of the most achievable goals and objectives that the educational learning process seeks to achieve.

Moreover, the detailed electronic feedback is important. It increases the learner's confidence in the validity of his learning results and makes the educational process more profound. It is also considered a guarantee for the success of the educational process because it allows the teacher and the learner to adapt their behavior in line with each of them, so the interaction between them becomes more positive.

There have been many modern teaching and learning methods that helped achieve practical educational goals in reaching learning different and varied skills, taking into account the shortening aspect of time and effort. This diversity of methods made educators reconsider the educational methods in the physical and pedagogical side. There is no doubt that the educational methods have a major role in reducing time and effort in the education process. Since the detailed electronic feedback is one of these methods, it must have the same results of improving and accelerating the educational process.

Also, according to the researcher's knowledge, there is no study on the use of electronic detailed feedback, its effect on some biomechanical indicators and the level of skill performance of high jump players. From here, the research problem appeared in its being a scientific attempt to know the effectiveness and impact of using electronic detailed feedback on the development of the level of skill performance for high jump players by studying some biomechanical indicators of the two stages of upgrading and flying in the high jump, considering these two stages are the most important and most influential in the level of skill performance of the high jump.

\section{Research Objective}

The research aims to identify the effect of using detailed electronic feedback on some biomechanical indicators and the skill level of high jump players through:

1. Measuring the effect of detailed electronic feedback on some biomechanical indicators of the upgrading and flight stages in the high jump

2. Measuring the effect of detailed electronic feedback on the level of skill performance in the high jump

\section{Research Importance}

1. Studying the effectiveness of electronic detailed feedback on some biomechanical indicators of the upgrading and flight stages in the high jump.

2. Studying the effectiveness of electronic detailed feedback on the level of skill performance in the high jump.

3. Upgrading the scientific and technical level of learners and introducing modern teaching environments

4. Keeping pace with the modern educational trends that concern the learner and making it an effective element in the educational process 


\section{Research Hypotheses}

1. There are statistically significant differences at the level of significance $(0.05)$ between the averages of the pre and post measurements of the research sample in some biomechanical indicators for the stages of upgrading and flight in the high jump.

2. There are statistically significant differences at the level of significance $(0.05)$ between the averages of the pre and post measurements of the research sample in the level of skill performance in the high jump.

\section{Research Terms}

- Detailed Feedback: it is detailed information that supports the learner to improve his learning outcomes, whether this information tells him his correct path in performing activities or his wrong path or the extent of his progress in learning by detailing his mistakes or what he did correctly in personal learning environments. (Fouad, 2013, p. 295)

- Electronic Detailed Feedback: the researcher defines it procedurally as a process that clarifies and explains the learner's response, whether right or wrong, explains and interprets the causes of the error and provides the learner with the directions and instructions necessary to reinforce, develop, or correct the behavior. This is presented electronically by the computer. $(*)$

- Biomechanical Indicators: are those indicators that are concerned with studying human movement during the performance of the kinetic action to obtain the desired and wanted goal and reach the high level. (Marwa, 2015, p. 32)

\section{Research Methodology}

The researcher used the experimental approach using The descriptive method and the experimental method with a single group design the experimental design for one experimental group by making the two pre and post measurements, due to its suitability for the nature of this research.

\section{Research Community}

The research community in the field of athletics for the academic year 2020/2021 is represented by the 6 students of the Faculty of Physical Education - Fayoum University and registered with the Egyptian Athletics Federation.

\section{Research Sample}

The researcher selected the research sample by the deliberate method from the specialization of athletic sports at the Faculty of Physical Education - Fayoum University. The number of (6) students are registered in the Egyptian Athletics Federation with a percentage of $(100 \%)$ of the research community. The researcher has also made use of (3) players from the same age stage from the Fayoum governorate club and from those who are registered in the Egyptian Athletics Federation to conduct scientific transactions for the tests, and they are the exploratory pilot study.

* Procedural Definition 


\section{Homogeneity of the Research Sample}

Table No. (1)

The mean, median, standard deviation and torsion coefficient of the research sample

\begin{tabular}{|c|c|c|c|c|c|c|c|c|c|}
\hline \multirow{3}{*}{$\begin{array}{c}\text { Statistics } \\
\text { Variables }\end{array}$} & \multirow{3}{*}{$\begin{array}{c}\text { Measuring } \\
\text { Unit }\end{array}$} & \multirow{2}{*}{\multicolumn{4}{|c|}{ Basic Sample (N=6) }} & \multirow{2}{*}{\multicolumn{4}{|c|}{ Exploratory Sample $(\mathrm{N}=3)$}} \\
\hline & & & & & & & & & \\
\hline & & Mean & Median & $\begin{array}{l}\text { Standard } \\
\text { Deviation }\end{array}$ & $\begin{array}{c}\text { Torsion } \\
\text { Coefficient }\end{array}$ & Mean & Median & $\begin{array}{l}\text { Standard } \\
\text { Deviation }\end{array}$ & $\begin{array}{c}\text { Torsion } \\
\text { Coefficient }\end{array}$ \\
\hline Age & Year & 20.667 & 21.000 & 0.516 & -0.968 & 20.667 & 21.000 & 0.577 & -1.732 \\
\hline Length & $\mathbf{c m}$ & 176.667 & 178.000 & 4.719 & -0.561 & 180.333 & 181.000 & 3.055 & -0.935 \\
\hline Weight & Kg & 66.833 & 68.500 & 5.981 & -1.374 & 69.667 & 73.000 & 7.572 & -1.597 \\
\hline $\begin{array}{c}\text { Skill } \\
\begin{array}{c}\text { Performance } \\
\text { Level }\end{array} \\
\end{array}$ & Meter & 169.500 & 169.500 & 2.881 & -0.452 & 173.000 & 174.000 & 2.646 & -1.458 \\
\hline
\end{tabular}

It is evident from Table (1) that the values of the torsion coefficients for the experimental group ranged between (-0.967: -1.374). Besides, the values of the torsion coefficients for the exploratory pilot study ranged between $(-0.935:-1.732)$. All these values occur between $( \pm 3)$ indicating the homogeneity of the members of the exploratory group and the homogeneity of the members of the exploratory sample.

\section{Methods of Data Collection}

- Devices and utilities for data collection

- Ristameter to measure length

- Medical scale to measure weight

- Mattresses

- High jump device

- Stopwatch

- Reviewing expert opinion and personal interview

- Kinetic analysis tools

- Hp core i7 computer

- Simi motion analysis software

- Two video cameras, 125 cadres / second

- Display device (Data Show)

- Used Tests

- Skill Performance Level (Player Digital Level)

- Biomechanical indicators: After reviewing the scientific references and previous studies such as (Al-Daly, 2017), (Marwa, 2015), (Badran, 2015), (Al-Badri, 2015), (Hassan \& Al-Badri, 2015) and surveying the opinion of the experts, the researcher found that the most important stages of performance in the high jump are the two phases of upgrading and flight that affect the level of performance of the skill of the high jump. The most important biomechanical indicators, which were agreed upon by the opinion of experts with a percentage greater than $70 \%$, are as follows:

- The Take-off stage, in which the biomechanical indicators are divided as follows:

a. Ground contact moment

1 - The net velocity of the wrist upgrading foot

2- The height of the general body weight center

3- The horizontal velocity of the general body weight center 
4- The vertical velocity of the general body weight center

5- Right knee angle

6- Left knee angle

7- Right torso angle

8- Left stem angle

9- Right elbow angle

10- The left elbow angle

11- Corridor distance

12- Backrest time

13- Rear tilt angle

b. Damping Moment

1- Right elbow angle

2- The left elbow angle

3- The percentage of damping

4- Back tilt angle

c. No ground contact moment

1- The time of upgrading

2- The upgrading distance

3- Flight angle

4- After the upgrading point of the bar

- The flight stage, in which the biomechanical indicators are divided as follows:

1- The horizontal velocity of the general body weight center

2- The vertical velocity of the general body weight center

3 - The angle of rotation of the shoulders on the longitudinal axis

4- Flying angle

5- The position of the highest point of the general body weight center over the bar

6-The resultant velocity of the general body weight center

Electronic Detailed Feedback Program (Appendix (3))

The researcher applied the detailed electronic feedback program for period of (6) weeks with one educational unit per week according to the curriculum for the specialization of athletic sports at the Faculty of Physical Education - Fayoum University and according to their course descriptions. The one educational unit included an explanation of the skill in question by the course professor (this is regarding the educational section is concerned) every educational unit is (90) minutes the Electronic Detailed Feedback Program take (15) minutes. As for the applied section, it includes the process of performance and repetition by the learners of the kinetic skill under study. Besides, the application part includes a video recording of a number of frequencies at the end of this part of the skill flow line for all the research sample and in which the detailed electronic feedback is given by the projector (data show) on the skill performance of the experimental group.

Exploratory study

The researcher conspicuously conducted the exploratory study on the exploratory pilot study in order to ascertain the scientific parameters of the level of skill performance (validity reliability) in the high jump. This is in addition to find out the problems that may face the researcher during the application of the detailed electronic feedback program. The researcher also used the exploratory study to prepare a photography place, setting up the camera and preparing the player for filming, in the period from 25/10/2020 to 28/10/2020. 


\section{Basic Study}

After the exploratory experiment achieved its objectives and the researcher was able to know the problems that may be encountered and encountered during the measurements and photographing and can overcome them within the limits of the available capabilities, the researcher conducted the following:

- Pre-measurement: The researcher made pre-measurements of the research sample, as well as completed imaging and Kinetic analysis procedures from 11/11/2020 to 4/11/2020.

- Application of the experiment: The researcher applied the experiment for the research sample for a period of (6) weeks with one educational unit per week from 7/11/2020 to $19 / 12 / 2020$

- Post measurement: The researcher made post measurements of the research sample, as well as completed photographing and Kinetic analysis procedures from 20/12/2020 to 23/12/2020.

\section{Statistical Processors}

- The Arithmetic Mean

- Standard Deviation

- Correlation Coefficient

- Wilcoxon Signed-rank Test

- The Median

- Torsion Coefficient

- Mann-Whitney Test

- Magnitude Amount of the Effect

- The researcher documented the scientific references in the (APA7) Approach according to the recommendations of the American Psychological Association, $7^{\text {th }}$ edition

- The researcher is satisfied with three digits after the decimal point and with the level of significance (0.05)

\section{Presentation and Discussion of Results \\ First: Presentation of Results}

Table No. (4)

The significance of the differences in the Non-parametric Wilcoxon Approach between the pre and post measurements of the biomechanical indicators of the Take-off stage in the high jump

$(\mathrm{N}=6)$

\begin{tabular}{|c|c|c|c|c|c|c|c|c|c|c|}
\hline & \multirow{2}{*}{$\begin{array}{l}\text { Statistics } \\
\text { Variables }\end{array}$} & \multicolumn{3}{|c|}{ Ranks } & \multirow{2}{*}{\multicolumn{2}{|c|}{$\begin{array}{c}\text { Ranks } \\
\text { Average }\end{array}$}} & \multicolumn{2}{|c|}{ Ranks Sum } & \multirow{2}{*}{$\begin{array}{c}\text { Value } \\
(\mathrm{Z})\end{array}$} & \multirow{2}{*}{$\begin{array}{c}\text { Significance } \\
\text { Level }\end{array}$} \\
\hline & & - & + & $=$ & & & - & + & & \\
\hline \multirow{11}{*}{$\begin{array}{l}\text { Ground } \\
\text { contact } \\
\text { moment }\end{array}$} & $\begin{array}{c}\text { The resultant velocity } \\
\text { of the upgrading foot } \\
\text { wrist }\end{array}$ & 6.000 & 0.000 & 0.000 & 3.500 & 0.000 & 21.000 & 0.000 & -2.201 & 0.028 \\
\hline & $\begin{array}{l}\text { The height of the } \\
\text { general body weight } \\
\text { center }\end{array}$ & 6.000 & 0.000 & 0.000 & 3.500 & 0.000 & 21.000 & 0.000 & -2.201 & 0.028 \\
\hline & $\begin{array}{l}\text { The horizontal velocity } \\
\text { of the general body } \\
\text { weight center }\end{array}$ & 0.000 & 6.000 & 0.000 & 0.000 & 3.500 & 0.000 & 21.000 & -2.201 & 0.028 \\
\hline & $\begin{array}{l}\text { The vertical velocity of } \\
\text { the general body } \\
\text { weight center }\end{array}$ & 5.000 & 0.000 & 1.000 & 3.000 & 0.000 & 15.000 & 0.000 & -2.023 & 0.043 \\
\hline & Right knee angle & 0.000 & 6.000 & 0.000 & 0.000 & 3.500 & 0.000 & 21.000 & -2.201 & 0.028 \\
\hline & Left knee angle & 5.000 & 1.000 & 0.000 & 4.000 & 1.000 & 20.000 & 1.000 & -1.992 & 0.046 \\
\hline & Right torso angle & 6.000 & 0.000 & 0.000 & 3.500 & 0.000 & 21.000 & 0.000 & -2.201 & 0.028 \\
\hline & Left torso angle & 0.000 & 6.000 & 0.000 & 0.000 & 3.500 & 0.000 & 21.000 & -2.201 & 0.028 \\
\hline & Right elbow angle & 0.000 & 6.000 & 0.000 & 0.000 & 3.500 & 0.000 & 21.000 & -2.201 & 0.028 \\
\hline & Left elbow angle & 0.000 & 6.000 & 0.000 & 0.000 & 3.500 & 0.000 & 21.000 & -2.201 & 0.028 \\
\hline & Back foothold distance & 0.000 & 5.000 & 1.000 & 0.000 & 3.000 & 0.000 & 15.000 & -2.041 & 0.041 \\
\hline
\end{tabular}




\begin{tabular}{ccccccccccc}
\hline \hline & Back support time & 6.000 & 0.000 & 0.000 & 3.500 & 0.000 & 21.000 & 0.000 & -2.333 & 0.020 \\
\cline { 2 - 10 } & Back tilt angle & 6.000 & 0.000 & 0.000 & 3.500 & 0.000 & 21.000 & 0.000 & -2.214 & 0.027 \\
\hline \multirow{2}{*}{$\begin{array}{c}\text { Dampin } \\
\text { g }\end{array}$} & Right elbow angle & 0.000 & 6.000 & 0.000 & 0.000 & 3.500 & 0.000 & 21.000 & -2.201 & 0.028 \\
\cline { 2 - 10 } & Left elbow angle & 5.000 & 1.000 & 0.000 & 4.000 & 1.000 & 20.000 & 1.000 & -1.992 & 0.046 \\
\cline { 2 - 10 } & $\begin{array}{c}\text { The percentage of } \\
\text { damping }\end{array}$ & 6.000 & 0.000 & 0.000 & 3.500 & 0.000 & 21.000 & 0.000 & -2.201 & 0.028 \\
\cline { 2 - 9 } & Back tilt angle & 0.000 & 6.000 & 0.000 & 0.000 & 3.500 & 0.000 & 21.000 & -2.201 & 0.028 \\
\hline $\begin{array}{c}\text { No } \\
\text { ground } \\
\text { contact } \\
\text { moment }\end{array}$ & \begin{tabular}{c} 
Upgrading time \\
\cline { 2 - 9 }
\end{tabular} & 6.000 & 0.000 & 0.000 & 3.500 & 0.000 & 21.000 & 0.000 & -2.214 & 0.027 \\
\cline { 2 - 9 } & $\begin{array}{c}\text { Upgrading distance } \\
\text { Flight angle }\end{array}$ & 0.000 & 6.000 & 0.000 & 0.000 & 3.500 & 0.000 & 21.000 & -2.232 & 0.026 \\
\hline \hline & $\begin{array}{c}\text { The distance of } \\
\text { upgading point of the } \\
\text { bar }\end{array}$ & 6.000 & 0.000 & 0.000 & 3.500 & 0.000 & 21.000 & 0.000 & -2.214 & 0.027 \\
\hline \hline
\end{tabular}

It is evident from Table (4) that there are statistically significant differences between the averages of the pre and post measurements of the biomechanical indicators of the stage of upgrading in the high jump of the individuals of the research sample. Besides, it is clear that all the biomechanical indicators under investigation for the stage of upgrading in the high jump have a level of significance. Moreover, all their values are less than the level of significance (0.05). This indicates the existence of differences between those indicators in the Take-off stage in favor of the post measurement of the experimental group.

Table No. (5)

The significance of the differences in the Non-parametric Wilcoxon Approach between the pre and post measurements of the biomechanical indicators of the flight stage in the high jump

\begin{tabular}{|c|c|c|c|c|c|c|c|c|c|}
\hline \multirow{3}{*}{$\begin{array}{c}\text { Statistics } \\
\text { Variables } \\
\begin{array}{c}\text { The horizontal velocity of the } \\
\text { general body weight center }\end{array}\end{array}$} & \multicolumn{3}{|c|}{ Ranks } & \multirow{2}{*}{\multicolumn{2}{|c|}{$\begin{array}{c}\text { Ranks } \\
\text { Average }\end{array}$}} & \multicolumn{2}{|c|}{ Ranks Sum } & \multirow{3}{*}{$\begin{array}{c}\begin{array}{c}\text { Value } \\
(\mathbf{Z})\end{array} \\
-2.201\end{array}$} & \multirow{3}{*}{$\begin{array}{c}\begin{array}{c}\text { Significance } \\
\text { Level }\end{array} \\
0.028\end{array}$} \\
\hline & \multirow{2}{*}{$\begin{array}{c}- \\
0.000\end{array}$} & \multirow{2}{*}{$\frac{+}{6.000}$} & \multirow{2}{*}{$\begin{array}{c}= \\
0.000\end{array}$} & & & \multirow{2}{*}{$\begin{array}{c}- \\
0.000\end{array}$} & \multirow{2}{*}{$\frac{+}{21.000}$} & & \\
\hline & & & & 0.000 & 3.500 & & & & \\
\hline $\begin{array}{l}\text { The vertical velocity of the } \\
\text { general body weight center }\end{array}$ & 0.000 & 6.000 & 0.000 & 0.000 & 3.500 & 0.000 & 21.000 & -2.201 & 0.028 \\
\hline $\begin{array}{l}\text { The angle of rotation of the } \\
\text { shoulders on the longitudinal } \\
\text { axis }\end{array}$ & 6.000 & 0.000 & 0.000 & 3.500 & 0.000 & 21.000 & 0.000 & -2.264 & 0.024 \\
\hline Flying angle & 0.000 & 6.000 & 0.000 & 0.000 & 3.500 & 0.000 & 21.000 & -2.226 & 0.026 \\
\hline $\begin{array}{l}\text { The position of the highest } \\
\text { point of the general body } \\
\text { weight center over the bar }\end{array}$ & 0.000 & 6.000 & 0.000 & 0.000 & 3.500 & 0.000 & 21.000 & -2.201 & 0.028 \\
\hline $\begin{array}{l}\text { The resultant velocity of the } \\
\text { general body weight center }\end{array}$ & 0.000 & 6.000 & 0.000 & 0.000 & 3.500 & 0.000 & 21.000 & -2.201 & 0.028 \\
\hline
\end{tabular}

Table (5) shows that there are statistically significant differences between the averages of the pre and post measurements of the biomechanical indicators of the flight phase in the high jump of the individuals of the research sample. Besides, it is clear that all the biomechanical indicators under investigation for the flight phase in the high jump have a level of significance, all of whose values are less than the level of significance (0.05). This indicates that there are differences between those indicators in the flight phase and in favor of the post measurement of the experimental group. 
Table No. (6)

The significance of the differences in the Non-parametric Wilcoxon Approach between the pre and post measurements of the level of skill performance in the high jump

$(\mathrm{N}=6)$

\begin{tabular}{|c|c|c|c|c|c|c|c|c|c|}
\hline \multirow{2}{*}{$\begin{array}{l}\text { Statistics } \\
\text { Variables }\end{array}$} & \multicolumn{3}{|c|}{ Ranks } & \multirow{2}{*}{\multicolumn{2}{|c|}{ Ranks Average }} & \multicolumn{2}{|c|}{ Ranks Sum } & \multirow{2}{*}{$\begin{array}{l}\text { Value } \\
(\mathrm{Z})\end{array}$} & \multirow{2}{*}{$\begin{array}{c}\text { Significance } \\
\text { Level }\end{array}$} \\
\hline & - & + & $=$ & & & - & + & & \\
\hline $\begin{array}{c}\text { Skill Performance } \\
\text { Level }\end{array}$ & 0.000 & 6.000 & 0.000 & 0.000 & 3.500 & 0.000 & 21.000 & -2.232 & 0.026 \\
\hline
\end{tabular}

Table (6) shows that there are statistically significant differences between the averages of the pre and post measurements of the level of skill performance in the high jump of the individuals of the research sample. Besides, we find that the value of the level of significance is smaller than the level of significance (0.05), which indicates the existence of differences in the level of skill performance and in favor of the post measurement of the experimental group.

Table No. (7)

The mean and standard deviation of the biomechanical indicators of the experimental group in the pre and post measurements of the Take-off stage in the high jump

$(\mathrm{N}=6)$

\begin{tabular}{|c|c|c|c|c|c|c|c|}
\hline \multirow{2}{*}{\multicolumn{2}{|c|}{$\begin{array}{l}\text { Statistics } \\
\text { Variables }\end{array}$}} & \multicolumn{2}{|c|}{ Pre-Test } & \multicolumn{2}{|c|}{ Post-Test } & \multirow[b]{2}{*}{$\begin{array}{l}\text { Effect } \\
\text { Volume }\end{array}$} & \multirow[b]{2}{*}{ Amount } \\
\hline & & Mean & $\begin{array}{l}\text { Standard } \\
\text { Deviation }\end{array}$ & Mean & $\begin{array}{l}\text { Standard } \\
\text { Deviation }\end{array}$ & & \\
\hline \multirow{13}{*}{$\begin{array}{l}\text { Ground } \\
\text { contact } \\
\text { moment }\end{array}$} & $\begin{array}{c}\text { The resultant velocity of the } \\
\text { upgrading foot wrist }\end{array}$ & 5.749 & 5.201 & 4.265 & 4.126 & 0.613 & Medium \\
\hline & $\begin{array}{c}\text { The height of the general } \\
\text { body weight center }\end{array}$ & 0.125 & 0.096 & -0.019 & 0.010 & 1.553 & Large \\
\hline & $\begin{array}{c}\text { The horizontal velocity of } \\
\text { the general body weight } \\
\text { center }\end{array}$ & 3.756 & 2.203 & 6.696 & 2.264 & 1.316 & Large \\
\hline & $\begin{array}{l}\text { The vertical velocity of the } \\
\text { general body weight center }\end{array}$ & 0.523 & 0.519 & 0.226 & 0.625 & 0.517 & Medium \\
\hline & Right knee angle & 69.372 & 7.033 & 116.242 & 4.597 & 7.889 & Large \\
\hline & Left knee angle & 150.435 & 14.388 & 89.988 & 71.172 & 1.177 & Large \\
\hline & Right torso angle & 170.654 & 5.659 & 149.341 & 7.816 & 3.124 & Large \\
\hline & Left torso angle & 154.308 & 2.031 & 161.295 & 3.241 & 2.583 & Large \\
\hline & Right elbow angle & 119.699 & 17.892 & 164.599 & 6.208 & 3.353 & Large \\
\hline & Left elbow angle & 132.398 & 6.440 & 153.504 & 9.552 & 2.591 & Large \\
\hline & Back foothold distance & 0.202 & 0.019 & 0.218 & 0.026 & 0.703 & Medium \\
\hline & Back support time & 0.053 & 0.004 & 0.044 & 0.004 & 2.250 & Large \\
\hline & Back tilt angle & 69.500 & 2.345 & 63.833 & 2.483 & 2.347 & Large \\
\hline \multirow{4}{*}{$\begin{array}{l}\text { Damping } \\
\text { Moment }\end{array}$} & Right elbow angle & 99.315 & 17.340 & 121.635 & 21.482 & 1.143 & Large \\
\hline & Left elbow angle & 126.567 & 4.225 & 91.189 & 22.981 & 2.141 & Large \\
\hline & The percentage of damping & 39.333 & 3.777 & 32.583 & 1.800 & 2.282 & Large \\
\hline & Back tilt angle & 79.833 & 2.317 & 84.333 & 2.944 & 1.699 & Large \\
\hline \multirow{4}{*}{$\begin{array}{c}\text { No } \\
\text { ground } \\
\text { contact } \\
\text { moment }\end{array}$} & Upgrading time & 0.157 & 0.006 & 0.151 & 0.006 & 1.000 & Large \\
\hline & Upgrading distance & 0.647 & 0.029 & 0.695 & 0.019 & 1.958 & Large \\
\hline & Flight angle & 16.500 & 2.074 & 19.500 & 1.975 & 1.481 & Large \\
\hline & $\begin{array}{c}\text { The distance of upgrading } \\
\text { point of the bar }\end{array}$ & 0.703 & 0.052 & 0.258 & 0.042 & 9.415 & Large \\
\hline
\end{tabular}

The magnitude of the effect from (0.20) to less than (0.50) is small, and from (0.50) to less than (0.80) medium, and from (0.80) to greater than that is large.

It is evident from Table (7) that the magnitude of the effect between the pre and post 
measurements of the mechanical indicators of the upgrading phase in the high jump for the members of the experimental group is large in all biomechanical indicators except for the ground contact moment in the upgrading phase in which both the velocity of the wrist of the upgrading foot and the vertical velocity of the general body weight center, the rear focal distance was the amount of the effect size for them average and that was in favor of the post measurement.

Table No. (8)

The mean and standard deviation of the biomechanical indicators of the experimental group in the pre and post measurements of the flight stage in the high jump

$(\mathrm{N}=6)$

\begin{tabular}{|c|c|c|c|c|c|c|}
\hline \multirow{2}{*}{$\begin{array}{c}\text { Statistics } \\
\text { Variables }\end{array}$} & \multicolumn{2}{|c|}{ Pre-Test } & \multicolumn{2}{|c|}{ Post-Test } & \multirow[b]{2}{*}{$\begin{array}{c}\text { Effect } \\
\text { Volume }\end{array}$} & \multirow[b]{2}{*}{ Amount } \\
\hline & Mean & $\begin{array}{l}\text { Standard } \\
\text { Deviation }\end{array}$ & Mean & $\begin{array}{l}\text { Standard } \\
\text { Deviation }\end{array}$ & & \\
\hline $\begin{array}{l}\text { The horizontal velocity of the general body } \\
\text { weight center }\end{array}$ & 2.089 & 0.954 & 2.602 & 1.022 & 0.519 & Medium \\
\hline $\begin{array}{c}\text { The vertical velocity of the general body } \\
\text { weight center }\end{array}$ & 1.605 & 1.549 & 3.303 & 1.231 & 1.214 & Large \\
\hline $\begin{array}{l}\text { The angle of rotation of the shoulders on the } \\
\text { longitudinal axis }\end{array}$ & 40.333 & 2.251 & 37.167 & 2.483 & 1.336 & Large \\
\hline $\begin{array}{c}\text { Flying angle } \\
\end{array}$ & 17.167 & 0.983 & 19.667 & 1.633 & 1.855 & Large \\
\hline $\begin{array}{l}\text { The position of the highest point of the } \\
\text { general body weight center over the bar }\end{array}$ & 0.994 & 0.046 & 1.138 & 0.170 & 1.156 & Large \\
\hline $\begin{array}{l}\text { The resultant velocity of the general body } \\
\text { weight center }\end{array}$ & 3.916 & 0.372 & 6.023 & 2.158 & 1.361 & Large \\
\hline
\end{tabular}

The magnitude of the effect from (0.20) to less than (0.50) is small, and from (0.50) to less than (0.80) was medium, and from (0.80) to greater than that was large.

It is evident from Table (8) that the amount of the effect size between the pre and post measurements of the mechanical indicators of the flight stage in the high jump for the members of the experimental group is large in all the biomechanical indicators in the flight stage and that was in favor of the post measurement except for the horizontal velocity index of the general body weight center, the effect was medium.

Table No. (9)

The mean and standard deviation of the level of skill performance of the experimental group in the pre and post measurements in the high jump

$(\mathrm{N}=6)$

\begin{tabular}{|c|c|c|c|c|c|c|}
\hline Statistics & \multicolumn{2}{|c|}{ Pre-Test } & \multicolumn{2}{|c|}{ Post-Test } & \multirow[b]{2}{*}{$\begin{array}{c}\text { Effect } \\
\text { Volume }\end{array}$} & \multirow[b]{2}{*}{ Amount } \\
\hline Variables & Mean & $\begin{array}{l}\text { Standard } \\
\text { Deviation }\end{array}$ & Mean & $\begin{array}{l}\text { Standard } \\
\text { Deviation }\end{array}$ & & \\
\hline Skill Performance Level & 169.500 & 2.881 & 182.667 & 2.066 & 5.252 & Large \\
\hline
\end{tabular}

The magnitude of the effect from (0.20) to less than (0.50) is small, and from (0.50) to less than $(0.80)$ is medium, and from (0.80) to greater than that large.

It is evident from Table (9) that the amount of the effect size between the pre and post measurements of the level of skill performance in the high jump for the members of the experimental group is large and that was in favor of the post measurement.

\section{Second: Discussing the Results}

The results in Table (4) and (5) indicate that there are statistically significant differences between the pre and post measurements in the biomechanical indicators of the high jump skill in the upgrading and flight stages. Conclusions and recommendations for players regarding the positions and angles of their bodies in the two stages of upgrading and flight in the high jump, as 
these two stages are the most dangerous stages that performance undergoes. Therefore, the recommendations and advice provided through the electronic feedback program had the best effect in improving some biomechanical indicators associated with the stages of upgrading and flight in the high jump.

The researcher also attributes to the effectiveness of using detailed electronic feedback the improvement that has been achieved in some biomechanical indicators of the two stages of upgrading and flying in the high jump, as the difficulty of some skills required to be learned and mastered requires the one who is in charge of the educational process to use and enter an auxiliary means (video or computer, for example) in his work in a manner that saves time and effort expended for the learner. Moreover, it is based on the involvement of some of the senses in the learning process, which leads to its deepening and asserting. Thus, it helps to create good and solid relationships between what he has learned and the consequent electronic detailed feedback that helps to improve the conditions of the body in those stages in a way that helps to reach the optimum performance.

The researcher also attributes this development to the effectiveness of the educational program prepared by the researcher, which relied on electronic detailed feedback. Besides, it relied on viewing the research sample for a number of frequencies of the performance path, which enhances the perceptions of movement in the research sample. Moreover, the repeated viewing adds a new vitality and dimension to the learning process. It transfers the learner from the traditional learning atmosphere to a state of excitement and attraction towards learning

The researcher also believes that the detailed electronic feedback works to expand the learners' perceptions through the possibility of exploiting more than one sense of learning because of its effect on creating an educational environment. It attracts the learner's attention, banishes the feeling of boredom, reinforces the educational material and broadens his perceptions.

Additionally, the researcher's findings are consistent with the results of some previous studies, such as the study of (Muhammad, 2008), (Kafafi, 2009), (Wahab, 2009), (Hendry, G.D., Bromberger, N., \& Armstrong, S., 2011), (Valdez, A., 2012), (Duffy, K., 2013), (Ramoud, 2013), (Al-Jazzar, 2014), (Fakhry, 2017), ( Jamal al-Din, 2017), (Mohammed, 2017).

\section{Thus, the first hypothesis of the search is fulfilled, which states that:}

"There are statistically significant differences between the averages of the pre and post measurements of the research sample in some biomechanical indicators of the upgrading and flight phases of the high jump".

The results in Table (6) indicate that there are statistically significant differences between the averages of the pre and post measurements of the level of skill performance in the high jump of the research sample individuals and for the benefit of the post measurement. Biomechanical indicators for the stages of upgrading and flight in the high jump allowed the learners to reach the optimal performance. This was in turn reflected in the level of skill performance and the digital level of the players in the skill of the high jump.

These results, which the researcher found out, are in line with the results of some previous studies, such as the study of (Al-Badri, 2015), (Al-Daly, 2017) indicating that improving some biomechanics' indicators of the high jump leads to an improvement in the level of skill performance as a whole. Moreover, this is reflected in the digital level of the player in the high jump.

Thus, the second hypothesis of the research is fulfilled, which states that:

"There are statistically significant differences between the averages of the pre and post 
measurements of the research sample in the level of skill performance in the high jump."

The results in Table (7) and (8) indicate that there is a difference in the arithmetic averages between the pre and post measurements, as well as the existence of statistically significant differences between the pre and post measurements in the biomechanical indicators of the stages of upgrading and flight. However, that difference, although it is a significant difference and is not due to chance, it does not tell us about the strength of the impact of the electronic feedback program on some biomechanical indicators of the stages of upgrading and flight in the high jump. So it was necessary to calculate the amount of the size of the effect between the two measurements before and after it to determine the strength of this relationship, which indicated the presence of a large impact size in most biomechanical indicators of the stages of upgrading and flight in the high jump except for the presence of a medium impact size at the moment of touch in the upgrading phase in the indicators of the velocity obtained for the wrist of the upgrading foot, the vertical velocity of the general center of gravity of the body, the distance of the rear focal point and also the size of the average impact in the horizontal velocity index of the general center of gravity of the body in the flight phase. Thus, the whole effect size for all biomechanical indicators of the upgrading and flight phases is large and medium thanks to the electronic detailed feedback program that the researcher followed with the members of the research sample.

This is in agreement with some previous studies, such as the study of (Hendry, G.D., Bromberger, N., \& Armstrong, S., 2011), (Mason, J.B. \& Bruning, R., 2011), (Valdez, A., 2012), (Duffy, K., 2013), (Ramoud, 2013), (Al-Jazzar, 2014), (Fakhry, 2017), ( Jamal al-Din, 2017), (Mohammed, 2017) which refers to the advantages of detailed electronic feedback as it helps:

- It stimulates the learners, as it helps them form positive attitudes towards the education process

- It achieves positive communication and strengthens cooperative relations between teachers and learners

- It supports higher-order thinking skills, critical thinking, cooperation, and relationship evaluation.

- It is based on important educational goals that are compatible with local and international standards

- It works to take into account the individual differences between the learners.

- It increases learners' satisfaction with the learning experience, and enhances their positive attitudes towards the learning process.

- It helps teachers follow learners individually or collectively as they share knowledge

- It provides a meaningful and rich environment for learners

\section{Conclusions}

1. The detailed electronic feedback has a positive and effective role in creating significant differences in some biomechanical indicators of performance in the high jump

2. The detailed electronic feedback has a positive and effective role in making significant differences in the skill level of the high jump

3. The detailed electronic feedback program had a clear and prominent role in creating a large size effect between pre and post measurement in some biomechanical indicators of the high jump

4. The detailed electronic feedback program had a clear and prominent role in creating a large size effect between pre and post measurement on the level of skill performance of the high jump 


\section{Recommendations}

1. Using detailed electronic feedback in other skills because of its positive effect on learning some kinetic skills.

2. Employing detailed feedback in detailed educational stages.

3. Paying attention to Kinetic analysis and biomechanical indicators in education because of their effective role in reaching optimal performance

4. Holding training courses for learners on how to employ detailed electronic feedback and Kinetic analysis in the educational process

\section{References}

Ahmed Mahmoud Al-Daly. (2017). The Effectiveness of the Torso Stability Training on some Biomechanical Properties and the Digital Achievement Level of the High Jump Competitors. Cairo: European Journal of Sports Science Technology.

Ahmed Mahmoud Fakhry. (2017). The Pattern of Feedback Based on Educational Analyzes in an Electronic Learning Environment to Develop the Skills of Website Production and Self-organization among Primary School Students, Scientific Production. Helwan University: Journal of Education Technology.

Asma Abdul-Raziq Jamal al-Din. (2017). The Effect of the Interaction of Feedback Patterns and the Cognitive Style in the Electronic Formative Assessment on Providing the Second Stage Pupils of Basic Education some Programming Skills, (Unpublished MA). Helwan University: Faculty of Education.

Asmaa Fathy Mohammed. (2017). The Effect of the Level of Feedback and the Method of Presenting it in Interactive Digital Stories on the Development of Achievement and Accomplishing Motivation among Primary School Students. (Unpublished PhD) Helwan University: Faculty of Education.

Rabih Abdel-Azim Ramoud. (2013). The Interaction between the Level of Feedback (Detailed Brief) and the Timing of its Presentation in Electronic Courses and its Effect on Achievement and Development of Visual Thinking among Students of the Faculty of Education. Cairo: Journal of Educational Technology, Issue 23.

Abdul Latif Al-Safi Al-Jazzar. (2014). The Effectiveness of Using two Types of Feedback in Computer Simulation Programs in Developing the Tasks of Learning to Solve Computer Operating Problems among Students of the Education Technology Department, scientific production. Benha University: Journal of the Faculty of Education.

Mazen Ahmed Marwa (2015). Biomechanics in sport. Beirut - Lebanon: Dar Al-Farabi.

Muhammad Abdul Hamid Hassan \& Muhammad Abdul-Wahhab Al-Badri (2015). Applications of Biomechanics in the Mathematical Field. Al-Zagazig: Zahraa Press.

Mohammed Ahmed Ramzi Badran. (2015). Principles of Biomechanics and its Applications in the Mathematical Field, 4th Ed. Al-Zagazig: Rasheed for publishing and distribution.

Mohammed Abdel-Wahab Al-Badri (2015). Biomechanical Indications for Additional Motivations for the Take-off stage in High Jump, Scientific Production Al-Zagazig University: Faculty of Physical Education for Males.

Muhammad Omar Muhammad (2008). The Effect of Patterns of Computerized Feedback and the Timing of its Presentation in Improving the Reading Comprehension of Students with Learning Difficulties in the United Arab Emirates (published PhD). Amman Arab University: Faculty of Higher Educational Studies.

Mahmoud Abdel Halim Abdul Karim (2006). The Dynamics of Teaching Physical Education. Cairo: Book Center for Publishing. 
Heba Othman Fouad (2013). Two Proposed Strategies for Feedback (Brief, Detailed) on Personal Learning Environments and their Effectiveness in Developing the Selforganization of Educational Technology Students. Cairo: Journal of Educational Technology, Volume 23, Issue 4.

Hoda Abdel Samea' Abdel Wahab (2009). The Effect of Immediate Feedback (Auditory and Visual) in Learning the under Skill Sending of Volleyball. Azza: Al-Fath Magazine, 42nd issue.

Wafaa Mustafa Kafafi (2009). The Effectiveness of Using Electronic Feedback in Developing the Skills of Preparing the Research Plan for Master's Students at King Abdulaziz University. Cairo: The Future of Arab Education Journal, Volume 16, Issue 58.

Walid Salem Al-Halafawi (2008). Educational Technology Innovations in the Information Age. Oman, Jordan: Dar Al-Fikr.

Brookhart, S.M) .2008.(How to give effective feedback to your students .ASCD: ERIC Number: ED509138.

Duffy, K) .2013.(Providing constructive feedback to students during mentoring .USA: Nursing standard, 27)31.(

Hendry, G.D ‘.Bromberger, N \& ‘.Armstrong, S) .2011 .(Constructive guidance and feedback for learning: The usefulness of exemplars, marking sheets and different types of feedback in a first year law subject .USA: Assessment and Evaluation in Higher Education.

Lemley, D ‘.Sudweeks, R ‘.Howell, S.R ‘.\& Laws, D.O) .2007 .(The effects of immediate and delayed feedback on secondary distance learnings . ,USA: the Quarterly Review Of Distance Education, 5(3), 251-260.

Mason, J.B g ‘.Bruning, R) .2011 .(Providing feedback in computer based instruction: What the research tells us, Manuscript retrieved March 7, 2011 .,from university of Nebraska center for instructional innovation: http://dwb.unl.edu/MB/Mason Bruning.html.

Nussabaumer, A·.\& Kravcik and Albert, D) .2012 .(Supporting Self Reflection in Personal Learning Environments through User Feedbck. In Proceedings of the 2 nd International Workshop on Personalization Approaches in Learning Environments (PALE) .montreal, canada: 20th Conference on User Modeling, Adaptation, and Personalization.

Smits, M.H ،.Boon, J.O g ،.Sluijsmans, D.M) . 2008 .(Content and timing of feedback in a webbased learning as a function of prior knowledge .USA: interactive learning environments, $16,(2), 183193$.

Valdez, A) .2012 Computer-based feedback and goal intervention learning effects .USA: Educational Technology Research and Development, 60 (5), 769-784.

Walsh, D) .2010 .(The Nurse Mentor's Handbook : Supporting Students in Clinical Practice . Maidenhead: Open University Press. 